\title{
The Effects of Intrathecal Administration of Excitatory Amino Acid Agonists and Antagonists on the Initiation of Locomotion in the Adult cat
}

\author{
J. R. Douglas, B. R. Noga, X. Dai, and L. M. Jordan \\ Department of Physiology, University of Manitoba, Winnipcg, Manitoba, Canada R3E OW3
}

Development of pharmacological strategies for the control of locomotion in patients with spinal cord injury or disease requires an understanding of the neuroactive substances involved in the activation of the spinal cord neural systems for the control of locomotion. Studies using the in vitro preparations of the lamprey, frog embryo, and newborn rat indicate that excitatory amino acids (EAAs) are involved in the initiation of locomotion. The present study determines whether spinal EAA receptors play a role in locomotion in an in vivo, adult mammalian preparation.

Experiments were performed on precollicular, postmammillary decerebrate cats, some of which were spinalized at the 13th thoracic segment. Cannulas for drug infusions were positioned intrathecally in the lumbar region of the spinal cord. A ligature around the spinal cord at the level of the 13th thoracic segment prevented rostral diffusion of the drugs. Locomotion was monitored with electromyograms in treadmill locomotion experiments and electroneurograms in fictive locomotion experiments.

Intrathecal infusion of either the NMDA receptor antagonist 2-amino-5-phosphonovaleric acid or the non-NMDA receptor antagonist 6-cyano-7-nitroquinoxaline-2,3-dione blocked hindlimb treadmill and fictive locomotion induced by electrical stimulation of the mesencephalic locomotor region (MLR) of the midbrain. Intrathecal administration of NMDA elicited hindlimb fictive locomotion in resting animals similar to that evoked by electrical stimulation of the MLR. At lower concentrations, NMDA evoked either independent bursting activity in the various nerves or loosely organized rhythmicity showing little reciprocity between antagonists. In contrast, administration of the EAA uptake blocker dihydrokainic acid (DHK) evoked intermittent periods of bursting activity characterized by a variable duration and a high degree of reciprocity between flexors and extensors. Given together at low concentrations, NMDA and DHK produced a well-coordinated locomotor pattern. Kainate and quisqualate were ineffective in producing fictive locomotion. These results are consistent with the suggestion that EAAs play a

\footnotetext{
Received Dec. 11, 1991; revised Sept. 3, 1992; accepted Sept. 9, 1992.

We thank K. Madec for technical assistance. This research was supported by a Medical Research Council of Canada (MRC) grant to L.M.J. and an MRC studentship to J.R.D., and by a Rick Hansen Man in Motion Legacy Fund studentship to X.D.

Correspondence should be addressed to Dr. L. M. Jordan, Department of Physiology, University of Manitoba, 770 Bannatyne Avenue, Winnipeg, Manitoba, Canada R3E 0W3.

Copyright $\odot 1993$ Society for Neuroscience $0270-6474 / 93 / 130990-11 \$ 05.00 / 0$
}

role in the initiation of mammalian locomotion. Furthermore, the results are consistent with those obtained from the neonatal rat in vitro preparations.

[Key words: excitatory amino acids, NMDA, non-NMDA, treadmill locomotion, fictive locomotion, intrathecal administration, decerebrate cat, mesencephalic locomotor region]

The introduction of new in vitro electrophysiological recording techniques in the early 1980s has increased our understanding of the rolc of cxcitatory amino acids (EAAs) in spinally mediated rhythmic motor activity. Poon (1980) and Cohen and Wallén (1980) were the first to show that bath application of either DIhomocysteate or D-glutamate (D-GLU) could elicit movements indistinguishable from normal swimming in a lamprey in vitro preparation. Subsequently, the NMDA receptor was implicated in the control of locomotion by Grillner and his colleagues. Bath-applied NMDA induced fictive locomotion (Grillner et al., 1981), while the NMDA receptor antagonist 2-amino-5phosphonovaleric acid (APV) reduced fictive locomotion elicited by NMDA (Brodin et al., 1985) and depressed spontaneous fictive swimming (Brodin and Grillner, 1985a). Bath application of kainate (KAIN), GLU, and NMDA (Roberts et al., 1983, 1986; Dale and Roberts, 1984; McClellan and Farel, 1985) also evokes fictive swimming in in vitro spinal amphibians. In the in vitro chick spinal cord, concurrent application of APV dosedependently reduced the locomotor activity cvoked with bathapplied NMDA (Barry and O'Donovan, 1987).

Experiments in higher animals have also shown the importance of EAAs in locomotion. Locomotion may be evoked following bath application of $N$-methyl-DL-aspartate (NMA) to the isolated cord of the newborn rat (Kudo and Yamada, 1987) and following bath application of NMA, NMDA, GLU, and amino acid uptake inhibitors to the spinal cord partition of an in vitro brainstem-spinal cord preparation (Smith and Feldman, 1987; Smith et al., 1988; Cazalets et al., 1990; Atsuta et al., 1991). The effects appear to be mediated through the activation of NMDA receptors at the spinal level since non-NMDA receptor agonists are only weakly effective or ineffective (Kudo and Yamada, 1987; Smith et al., 1988; but see Alford and Grillner, 1990). Recently, Fenaux et al. (1991) have shown the importance of NMDA receptors in the mediation of locomotion in deccrcbrate or spinal rabbits following systemic injections of the noncompetitive NMDA receptor antagonist MK-801.

EAAs are not the only transmitters that can evoke rhythmic activity following bath application at the spinal level (e.g., Smith and Feldman, 1987; Smith et al., 1988; Cazalets et al., 1990; Atsuta et al., 1991). However, several observations support the 
suggestion that EAAs might play a fundamental role in the activation of spinal locomotor neural circuits. (1) EAAs evoke locomotion in all species examined. (2) NMDA receptor antagonists block both spontaneous locomotion (Brodin and Grillner, 1985a) and the locomotion evoked by exposure of the spinal cord to various other neurotransmitter agonists (Smith et al., 1988; Schmidt et al., 1989; Fenaux et al., 1991). (3) The nonNMDA receptor antagonist 6-cyano-7-nitroquinoxaline-2,3dione (CNQX) suppresses the locomotion evoked by bath application of ACh to the in vitro neonatal rat spinal cord (Schmidt et al., 1989).

The present study was designed to investigate whether EAA receptors play a role in the spinal circuitry for locomotion in an adult mammal in vivo. Adult animals were used since recent evidence suggests that the relative distribution of NMDA receptors is different in the neonate and adult (Gonzalez et al., 1990). Decerebrate cats were used since locomotion is easily elicited in this preparation by electrically stimulating the mesencephalic locomotor region (MLR) in the midbrain, an area that activates the spinal locomotor neural circuits (for review, see Jordan, 1986, 1991) and that mediates the locomotion evoked from higher motor centers (Shik et al., 1968; Garcia-Rill, 1986). The ability of various drugs to initiate or block hindlimb locomotion evoked by stimulation of the MLR was tested by their intrathecal infusion into the lumbar region of the spinal cord.

A preliminary report of this work has appeared in abstract form (Douglas et al., 1990).

\section{Materials and Methods}

The data presented in this study were obtained from 27 cats weighing $2.4-4.0 \mathrm{~kg}$. Animals were initially anesthetized with halothane in a mixture of $70 \%$ nitrous oxide and $30 \%$ oxygen delivered through a face mask. The trachea was then intubated for direct administration of the anesthetic. The left common carotid artery was cannulated and connected to a pressure transducer for blood pressure monitoring. The right external jugular vein (and occasionally the left cephalic vein) was cannulated for administration of fluids. A bicarbonate/glucose buffer solution $(0.84 \mathrm{gm}$ sodium bicarbonate, $5 \mathrm{gm}$ glucose in $100 \mathrm{ml}$ water) was infused at $5 \mathrm{ml} / \mathrm{hr}$ throughout the experiment. Dextran (Travenol) was administered intravenously as necessary to maintain blood pressure at or above $80 \mathrm{~mm} \mathrm{Hg}$. Each animal was given $2 \mathrm{mg}$ dexamethasone (Hexadrol phosphate, Organon) to minimize tissue swelling. Body temperature was maintained at approximately $37^{\circ} \mathrm{C}$.

Treadmill locomotion experiments. In 13 experiments, treadmill locomotion was monitored using electromyographic (EMG) recordings obtained from the following muscles bilaterally: biceps brachii (BB), triceps brachii, lateral gastrocnemius (LG), and tibialis anterior (TA).

A laminectomy was performed, removing the 13th thoracic, and the 5th and 6th lumbar vertebrae. A 3-0 silk ligature was placed around the exposed thoracic spinal cord. At the caudal end of the exposed lumbar region, a small hole was made in the dura mater and the arachnoid on each side, slightly lateral to the dorsal root entry zone. PE10 Silastic tubing was inserted bilaterally through the holes into the subarachnoid space for intrathecal drug infusions. The tubing was passed rostrally underneath the dorsal roots to the region of the L4 spinal segment.

The head of each animal was placed in a stereotaxic headframe with all four limbs free to step on a treadmill belt. The hindquarters were supported by a sling under the abdomen. Immediately upon removal of the anesthetic, the animals were decerebrated with a precollicular, postmammillary transection of the brainstem. After a $1 \mathrm{hr}$ recovery period, locomotion was induced by electrical stimulation $(0.5-1.0 \mathrm{msec}$ pulses, $15-30 \mathrm{~Hz}, 10-220 \mu \mathrm{A}$ ) of the MLR as previously described (Jordan et al., 1979). EMGs were amplified, rectified, and integrated (envelope follower) before being digitized by a Masscomp computer for analysis.

Fictive locomotion experiments. To monitor locomotion in paralysed cats (14 experiments), various motor nerves were dissected free and cut and the proximal ends mounted for electroneurographic (ENG) recordings. Branches of the left femoral nerve were inserted into separate recording nerve cuff electrodes. The nerve branches included vastus lateralis, medialis, and intermedialis (VAST), rectus femoris (RF), quadriceps femoris (QUAD; includes RF and VAST mounted together), and sartorius (SA). The medial and anterior sartorius (SAm and SAa, respectively) were sometimes recorded separately. The right femoral nerve was cut to maintain symmetrical denervation on the two sides. The sciatic nerves were dissected bilaterally, placed in custom-made horizontal nerve trays, covered with warm mineral oil, and mounted on bipolar electrodes. The nerve branches included semimembranosus (SM), anterior biceps (AB), posterior biceps (PB), semitendinosus (ST), gastrocnemius-soleus (GS), or the medial and lateral heads of gastrocnemius (MG and LGs, respectively; the latter contained the nerve branch to soleus) and tibialis anterior (TA).

The thoracic spinal cord was exposed and a ligature placed around the spinal cord as in the treadmill locomotion experiments. A lumbar laminectomy (L3-L7 vertebrae) was performed, and cannulas for in trathecal drug infusions were inserted as described above.

Animals were transferred to a spinal frame with legs pendant. A back pool was formed and filled with mineral oil maintained at $37^{\circ} \mathrm{C}$ with a feedback-controlled heating lamp. The head of each animal was placed in a stereotaxic head holder. The anesthetic was removed and the animals were decerebrated with a precollicular, postmammillary transection of the brainstem. After a $1 \mathrm{hr}$ recovery period, the animals were paralyzed with 8-16 mg gallamine triethiodide (Flaxedil, Rhone-Poulenc) given intravenously (approximately $4 \mathrm{mg} / \mathrm{kg} / \mathrm{hr}$ ). Artificial ventilation was adjusted to maintain end-tidal $\mathrm{CO}_{2}$ at around $4 \%$. Locomotion was evoked by MLR stimulation (0.5-1.0 msec pulses, 13-20 $\mathrm{Hz}, 30-220 \mu \mathrm{A})$ and the ENG signals processed and recorded as described above. In one experiment the raw ENG signals were amplified, digitized, and captured at $8 \mathrm{kHz}$.

Drug trials. The ligature around the thoracic cord was tightened prior to each control trial just sufficiently to occlude the subarachnoid space but not enough to occlude the blood flow or damage the spinal cord. During this procedure, no overt behavioral effects were observed (movement or increase in EMG/ENG discharge rate). The ligature confined the spread of intrathecally administered fluids to the lumbar region of the spinal cord. This was visually verified after each experiment by infusion of the dye fast green. A hole was cut in the dura and arachnoid slightly caudal to the thoracic tie to allow overflow of excess fluid at the rostral end of the infusion area. Drugs were infused over a period of $1-$ 3 min to minimize the pressure increase within the intrathecal space. Drugs were dissolved in Elliott's solution A [artificial cerebrospinal fluid (CSF); Elliott and Jasper, 1949] for intrathecal administration; they included CNQX (6-cyano-7-nitroquinoxaline-2,3-dione; Tocris Ncuramin), DL-APV, dihydrokainic acid (DHK), NMDA, GLU, quisqualate (QUIS), and KAIN (Sigma). Injection volumes ranged from 0.25 to 0.5 ml through each intrathecal cannula. Drug concentrations ranged from 0.1 to $10 \mathrm{~mm}$ (usually $1.0 \mathrm{~mm}$ ). The injection volume retained within the intrathecal space ranged between 0.4 and $0.5 \mathrm{ml}$ (as determined from measurements of the excess fluid found extradurally in the thoracic and lumbar regions in seven cats). Intrathecal infusions of artificial CSF in volumes identical with those used in the drug trials served as controls.

The threshold strength to initiate locomotion by electrical stimulation of the MLR was recorded both before and after the control infusions of artificial CSF and following the infusions of APV and CNQX. In treadmill locomotion experiments, this represented the lowest current strength that could induce quadrupedal stepping within approximately $20 \mathrm{sec}$ of the start of the stimulation. In fictive locomotion experiments, the threshold for bipedal hindlimb stepping was measured, since the threshold for forelimb locomotion was often much greater. Control threshold strengths ranged from 30 to $140 \mu \mathrm{A}$ (mean, $91.0 \pm 30.3 \mu \mathrm{A}$; $n=10$ ) and from 30 to $170 \mu \mathrm{A}$ (mean, $110.5 \pm 49.2 \mu \mathrm{A} ; n=10$ ) for treadmill and fictive locomotion experiments, respectively.

After each experiment, the position of the tip of each intrathecal cannula was determined to ensure that the tubing was below the dorsal roots and that the infused drugs would reach the more ventral regions of the spinal cord.

Spinat preparations. Two decerebrate animals (from one treadmill and one fictive locomotion preparation) were spinalized by cooling or anesthetizing the exposed segment of the thoracic cord with either crushed, frozen Elliott's solution A or Xylocaine, respectively, tightening the ligature around the cord to prevent bleeding from the caudal portion, and finally, transecting the cord rostral to the ligature. Intrathecal drug 


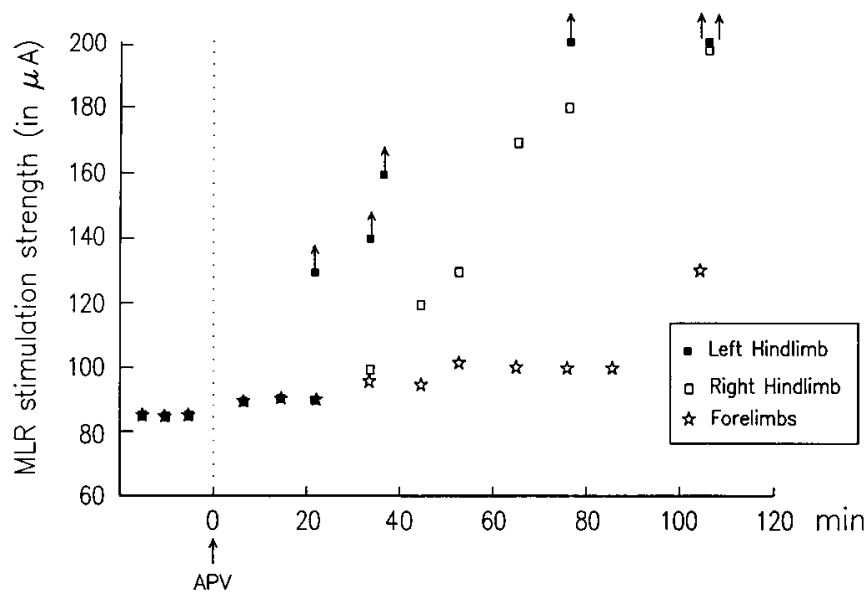

Figure 1. Effect of intrathecal administration of $1 \mathrm{~mm}$ APV on the electrical threshold for MLR-evoked quadrupedal locomotion. The electrical "threshold" was defined as the lowest MLR stimulation strength that could elicit treadmill locomotion in all four limbs. The arrows signify that no response could be elicited at the indicated current. In this example, 100 min after APV infusion, both hindlimbs dragged on the treadmill with strengths of stimulation of $200 \mu \mathrm{A}$. MLR stimulation parameters: $20 \mathrm{~Hz}, 0.5$-msec-duration pulses.

injections were then performed following a brief (60-120 min) recovery period.

\section{Results}

The infusions of artificial CSF at volumes equal to that infused during drug trials did not affect the threshold or ability of the MLR to evoke hindlimb locomotion. The mean change in the MLR threshold following control infusions of CSF was $0.5 \pm$ $6.9 \mu \mathrm{A}(n=14$; range, -20 to +10$)$ of the control. This shows that the effects seen after drug infusions cannot be attributed to an action of the artificial CSF itself, or to an increase in the pressure on the spinal cord at the time of injection. Furthermore, the spinal cord blood flow was not significantly impaired since tightening of the ligature did not affect the ability of the animal to locomote. Injections of fast green through the intrathecal cannulas after each experiment showed diffusion of the intrathecally administered fluids in the lumbosacral spinal cord region. The dye was usually evenly distributed throughout the subarachnoid space around the lumbar cord within 2-3 min of infusion.

\section{Effects of intrathecal EAA antagonists on $M L R$-evoked locomotion}

Intrathecal injection of the selective NMDA receptor antagonist APV (0.5-1.0 mM) increased the MLR stimulation strength needed to elicit hindlimb treadmill or fictive stepping within 15-20 min. The threshold continued to rise gradually, until eventually there was no hindlimb activity at stimulation currents of up to $220 \mu \mathrm{A}$ (Fig. 1), 30-100 min after APV administration. APV blocked MLR-evoked locomotion (Figs. 2, 3) in a total of six of nine treadmill experiments and six of six fictive locomotion experiments. The lowest concentration of APV capable of blocking MLR-evoked treadmill and fictive locomotion was $1.0 \mathrm{~mm}$ and $0.5 \mathrm{~mm}$, respectively. Although $1 \mathrm{~mm}$ was usually sufficient, the effective concentration varied from animal to animal and probably depended upon the relative distribution of the drug within the intrathecal space. Accordingly, the maximum concentration of APV required for complete block of MLR-evoked locomotion was 5 and $10 \mathrm{~mm}$ for fictive and treadmill locomotion preparations, respectively. Injection of 1 and $5 \mathrm{~mm}$ APV partially blocked MLR-evoked locomotion in two
Figure 2. Effects of $1 \mathrm{~mm}$ APV on MLR-evoked treadmill locomotion. APV decreased the amplitude of the EMG bursts $(B)$, leading to a complete block of hindlimb locomotion $(C), 30$ and 47 min following APV, respectively. Recovery was evident by $127 \mathrm{~min}$ $(D)$, the locomotion being similar to the control $(A)$. Note that, in this example, the frequency of hindlimb locomotion was not substantially altered with the partial block $(B)$. MLR stimulation strengths at $20 \mathrm{~Hz}, 0.5 \mathrm{msec}$ pulses were $110 \mu \mathrm{A}(A, B, D)$ and $120 \mu \mathrm{A}(C)$. In this and subsequent figures, the gain of each waveform is the same unless otherwise specified.

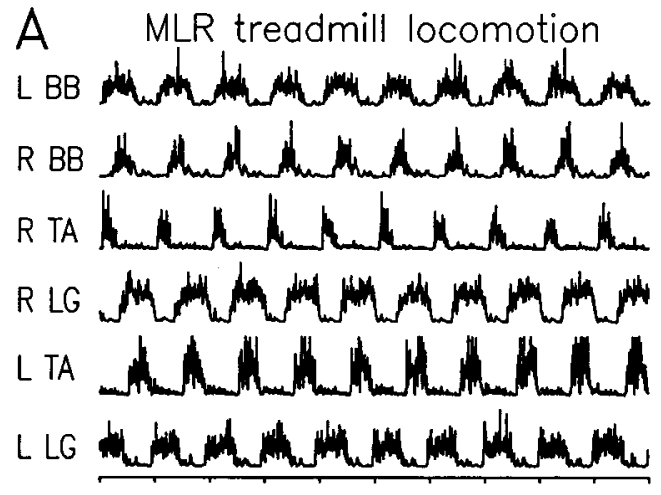

C $\quad$ APV $-47 \mathrm{~min}$

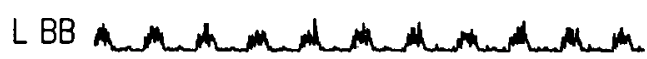

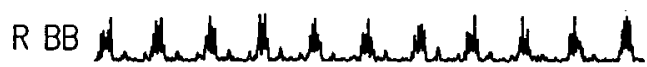

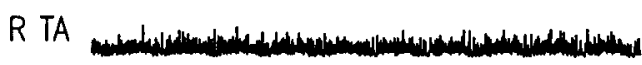

R LG

L TA

L LG

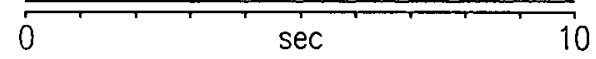

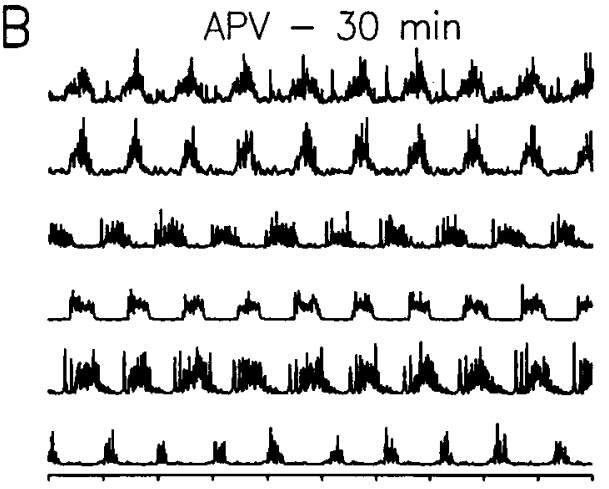

D recovery - $127 \mathrm{~min}$

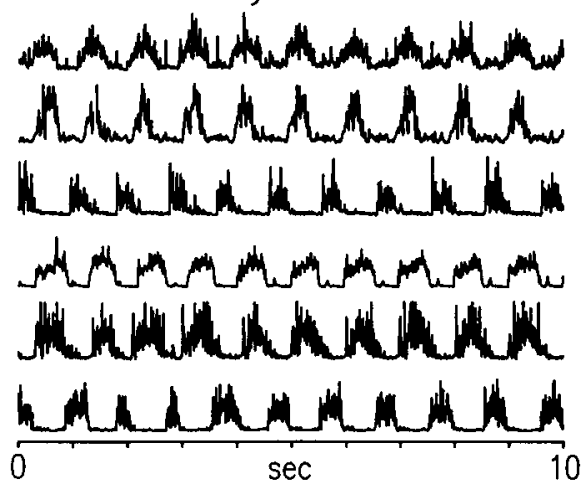


of nine treadmill locomotion experiments. In these cases, the EMG bursts were either abolished or decreased in amplitude, resulting in decreased limb excursions and less "vigorous" locomotor movements. In one treadmill experiment, injection of $10 \mathrm{~mm}$ APV had very little effect on MLR-evoked hindlimb locomotion. However, dye injection through the intrathecal cannulas in this experiment revealed a poor distribution of fluid within the subarachnoid space surrounding the spinal cord (and presumably within the spinal gray matter), with the ventral and most of the lateral surfaces not being in contact with the superfusate.

The progressive antagonism of MLR-evoked hindlimb locomotion with intrathecal administration of APV followed a consistent pattern: the amplitude of the EMG or ENG bursts gradually decreased, with the frequency of stepping initially remaining constant (compare Fig. $2 A, B$ ). In all but one fictive locomotion experiment, the frequency of hindlimb stepping became variable and/or decreased prior to complete block. In three treadmill locomotion experiments, the frequency of hindlimb locomotion remained similar to the frequency of forelimb stepping prior to complete block of hindlimb locomotion. In the treadmill locomotion experiments, the vigor of the hindlimb steps progressively decreased. First, the hindlimbs would undergo smaller excursions during the swing phase and the ankle would fail to extend such that the animal stepped on its toes rather than its footpads during the stance phase. Then the dorsum of the foot would be dragged along the treadmill throughout the step cycle. As the strength of the muscle contractions continued to decline, the legs would increasingly be pulled behind the animal by the moving treadmill belt. Just before all hindlimb activity ceased (Fig. $2 C$ ), weak contractions of the thigh muscles could be seen through the skin, sometimes occurring at the same frequency as the forelimb steps. In the two fictive locomotion experiments in which SA and QUAD ENGs were recorded, SA activity was the last to be blocked by APV.

Complete recovery of MLR-evoked hindlimb locomotion occurred 2.5-4 hr after APV (0.5-1.0 mM) administration in one treadmill and in two fictive locomotion experiments (Figs. $2 D$, $3 C$ ). In the treadmill locomotion experiment, the hindlimbs resumed walking at the same frequency as the forelimbs.

Partial recovery of MLR-evoked hindlimb locomotion was also observed in two additional treadmill experiments, 60 and $220 \mathrm{~min}$ following the infusion of $1 \mathrm{~mm} \mathrm{APV}$, and in one fictive locomotion experiment, $40 \mathrm{~min}$ after the infusion of $1 \mathrm{~mm}$ APV. No recovery of MLR-evoked locomotion was observed within 2-3 $\mathrm{hr}$ in other animals that had received equal or higher concentrations of APV.

In the treadmill experiments there was usually no change in forelimb locomotion after APV administration, which suggests that the loss of hindlimb locomotion was not due to a decline in the effectiveness of the MLR site, or to a general deterioration in the condition of the animal. However, forelimb locomotion became weaker (Fig. 2C) in the few instances associated with drug leakage rostral to the thoracic ligature.

The non-NMDA receptor antagonist CNQX (Honore et al., 1988) was administered intrathecally in three experiments. Injection of $2 \mathrm{mM} C N Q X$ resulted in a near-complete antagonism of MLR-evoked fictive locomotion (Fig. 4). In this experiment, the frequency and amplitude of MLR-evoked locomotion decreased progressively (Fig. 4B). By $113 \mathrm{~min}$, CNQX abolished rhythmic activity in most, but not all, nerves. A near complete recovery was observed by $273 \mathrm{~min}$ (Fig. $4 C$ ), although the frequency of locomotion obtained with the same MLR stimulation

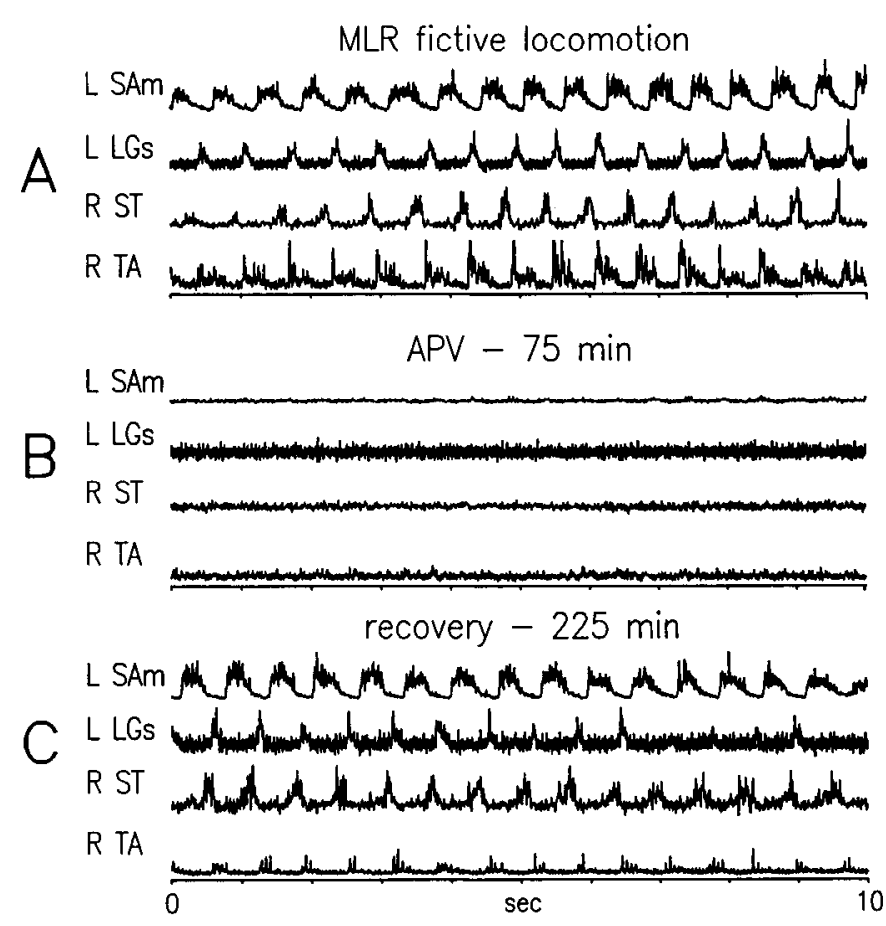

Figure 3. Demonstration of recovery of MLR-evoked hindlimb fictive locomotion following administration of $0.5 \mathrm{~mm}$ APV. $A$ shows the control hindlimb locomotion evoked with $80 \mu \mathrm{A}$ MLR stimulation. Hindlimb locomotion could not be elicited by stimulation of the MLR at strengths of $150 \mu \mathrm{A}$ (or higher), $75 \mathrm{~min}$ after APV (B). Stepping returned with $150 \mu \mathrm{A}$ MLR stimulation, $3 \mathrm{hr}$ and $45 \mathrm{~min}$ after APV (C). MLR stimulation parameters: $15 \mathrm{~Hz}, 1.0$-msec-duration pulses.

strength was lower than that observed during the control trial (Fig. 4A). In one other fictive locomotion experiment, administration of $1 \mathrm{mM} \mathrm{CNQX}$ resulted, within $10 \mathrm{~min}$, in an increase in the threshold for MLR-evoked locomotion, a decrease in the amplitude of ENG bursts, a decrease in the cycle frequency, and an increase in the cycle variability. Within $111 \mathrm{~min}$, the cycle frequency, variability, and burst amplitudes had returned to control values although the threshold for MLR-evoked locomotion had only partially recovered (double the control value of $50 \mu \mathrm{A}$ ). Finally, in one treadmill locomotion experiment, administration of $0.1 \mathrm{mM}$ CNQX frequently disrupted the normal reciprocal alternation of activity observed between antagonists on the same side, resulting in the appearance of considerable overlap of activity between flexors and extensors acting at the same joint. CNQX also resulted in a decrease in the amplitude of the ankle extensor EMGs bilaterally, with the loss of individual bursts of activity during the step cycle on the left side. The decreased EMG activity resulted in a progressive decline in the vigor of each hindlimb step (smaller excursions and decreased weight support during the stance phase). This effect was most prominent on the left side, and the animal appcarcd to "limp" with its left hindlimb. CNQX did not effect the frequency of stepping in this animal. CNQX produced the effects described above and increased the threshold for MLR-evoked locomotion within $56 \mathrm{~min}$ of its administration. Recovery was observed within $126 \mathrm{~min}$.

\section{Effects of intrathecal NMDA, L-GLU, and DHK}

Treadmill locomotion experiments. Attempts were made in five cats (four decerebrate, one decerebrate/spinal) to induce hind- 


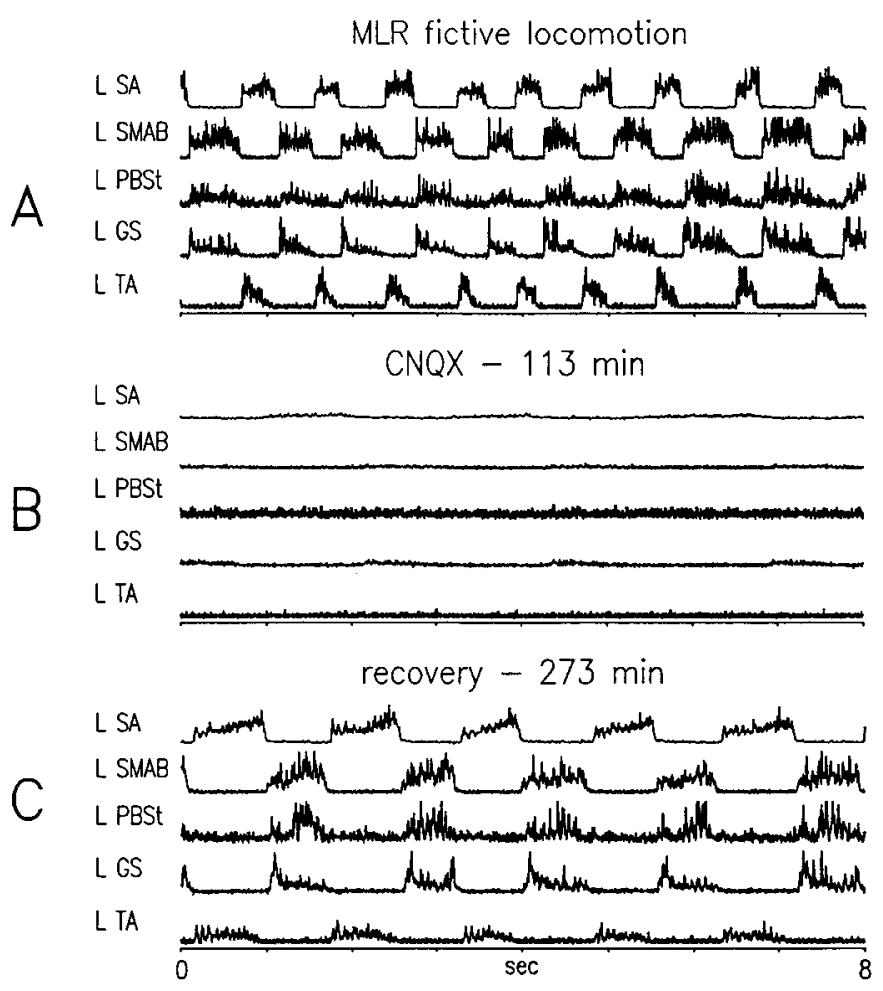

Figure 4. Effect of intrathecal administration of $2 \mathrm{~mm}$ CNQX on MLRevoked fictive locomotion. As illustrated in $B$, CNQX resulted in either a loss (nerves $L P B S t, L T A$ ) or a substantial reduction (nerves $L S A$, $L S M A B, L G S)$ in the ENG amplitude when compared to the control (A). Step cycle frequencies were also decreased substantially. By 273 min $(C)$, the amplitude of the ENG bursts had returned to near control values, although the step cycle frequency remained lower than the control. MIR stimulation parameters: $120 \mu \mathrm{A}, 14 \mathrm{~Hz}, 1$-msec-duration pulses.

limb stepping with NMDA $(0.1-10 \mathrm{~mm})$ in the absence of MLR stimulation. Three of the decerebrate animals had previously undergone an APV trial several hours before NMDA infusions were started, and two of these showed partial recovery from the effects of APV. One animal was spinalized $2 \mathrm{hr}$ before the NMDA infusion. In all four of the decerebrate animals there was an increase in hindlimb muscle tone, resulting in increased rigidity of the hindlimbs within 1-2 min of the intrathecal NMDA administration. In the decerebrate animal that had not received APV, administration of $5 \mathrm{~mm}$ NMDA resulted in short bouts $(5-10 \mathrm{scc})$ of hindlimb locomotion within $2.5 \mathrm{~min}$ and lasting up to $43 \mathrm{~min}$. In general, this locomotion showed reciprocal alternation of activity between flexors and extensors, although slight overlap of activity was occasionally observed. This activity was similar to that seen in control MLR-evoked locomotion. At the beginning of NMDA-evoked locomotion, limb excursions were qualitatively similar to those observed with MLR stimulation. However, the amplitude of the limb excursions rapidly became much smaller. Periods of rhythmic flexion movements or bilateral hindlimb extension usually separated the locomotor bouts. Intrathecal administration of NMDA in the other three decerebrate animals did not result in locomotor activity. In contrast, the ankle flexor (TA) ENG showed periodic bursts of activity of approximately $1 \mathrm{sec}$ duration. The bursts occurred sporadically with intervals of 3-10 sec and were occasionally observed bilaterally. Nonreciprocal extensor bursts were sometimes observed. There were also transient periods of profound hip, knee, and ankle flexion and forelimb extension initially lasting $1 \mathrm{~min}$ or more. These periods gradually decreased in duration. Brief oscillatory episodes resembling paw shakes (Smith et al., 1985; Koshland and Smith, 1989) occasionally interrupted the periods of hindlimb flexion. Intrathecal injection of $1 \mathrm{mM}$ NMDA into the spinal animal produced effects similar to those seen in the latter three decerebrate animals except that there was no forelimb involvement.

NMDA extended the locomotor period evoked by electrical stimulation of the MLR or by manual displacement of the forelimbs (forelimb swing) for up to $10 \mathrm{sec}$ after termination of the stimulus. In this animal, intrathecal infusion of NMDA was ineffective in evoking locomotion. Prolonged locomotion following MLR stimulation and forelimb-swing cvoked locomotion was not observed prior to the administration of NMDA.

NMDA was administered with DHK (0.5-2.5 mM total concentration) in two treadmill locomotion animals that had not previously received any drugs. In both cases nonspecific excitation occurred within 5-20 min, with long periods of hindlimb flexion, intermittent periods of vigorous shaking of the leg and trunk muscles, and sporadic locomotor episodes of two to four step cycles.

Fictive locomotion experiments. NMDA (1-5 mM) was intrathecally administered to five paralyzed decerebrate cats. Administration of $5 \mathrm{~mm}$ NMDA evoked locomotion in two animals (one of which had received CNQX $2 \mathrm{hr}$ previously). NMDA initially evoked bursts of activity from a variety of nerves (Fig. $5 B$ ), and subsequently, short bouts (5-20 sec) of hindlimb locomotion (Fig. $5 C$ ). This locomotion was characterized by the reciprocal alternation of activity of flexors and extensors and was similar to that evoked with stimulation of the MLR though it occurred at nearly twice the rate as the control in this experiment (compare Fig. 5, $C, E$ and $A, D$ ). Administration of $5 \mathrm{~mm}$ NMDA evoked locomotion similar to that shown in Figure 5 in the decerebrate animal that had previously received CNQX. In contrast, administration of $5 \mathrm{mM}$ NMDA failed to evoke locomotion in one animal that had received APV 4 hr earlier (see Fig. 7B). Instead, NMDA evoked intermittent bursts of rhythmic activity characterized by poor reciprocity between normally antagonistic nerves.

In two animals, administration of $1 \mathrm{~mm}$ NMDA failed to evoke ENG activity similar to the locomotion typically seen following MLR stimulation. Instead, NMDA initially evoked intermittent bursts $(1-10 \mathrm{sec})$ of activity in the flexor and extensor ENGs. This bursting activity was independent and could occur at different rates in the different nerves. Nlthough the bursting activity eventually became more rhythmic, it was typically characterized by poor reciprocity between flexors and extensors and thus a considerable amount of overlap (Fig. 6 A). The amount of overlap was much greater than that observed from locomotion evoked by $5 \mathrm{mM}$ NMDA (Fig. $5 C$ ) or stimulation of the MLR (Figs. $3 A, 4 A, 5 A$ ). However, reciprocally organized cycles were sometimes found interspersed between the overlapping cycles.

In contrast to the results obtained with $1 \mathrm{~mm}$ NMDA, administration of DHK either alone (Fig. 6B) or shortly after NMDA (Fig. $7 C$ ) produced alternating bursts of activity characterized by a high degree of reciprocity between most (but not necessarily all) flexors and extensors. Furthermore, DHK given in this manner evoked bursts of variable duration that differed from that evoked by MLR stimulation (Fig. $7 A$ ). 


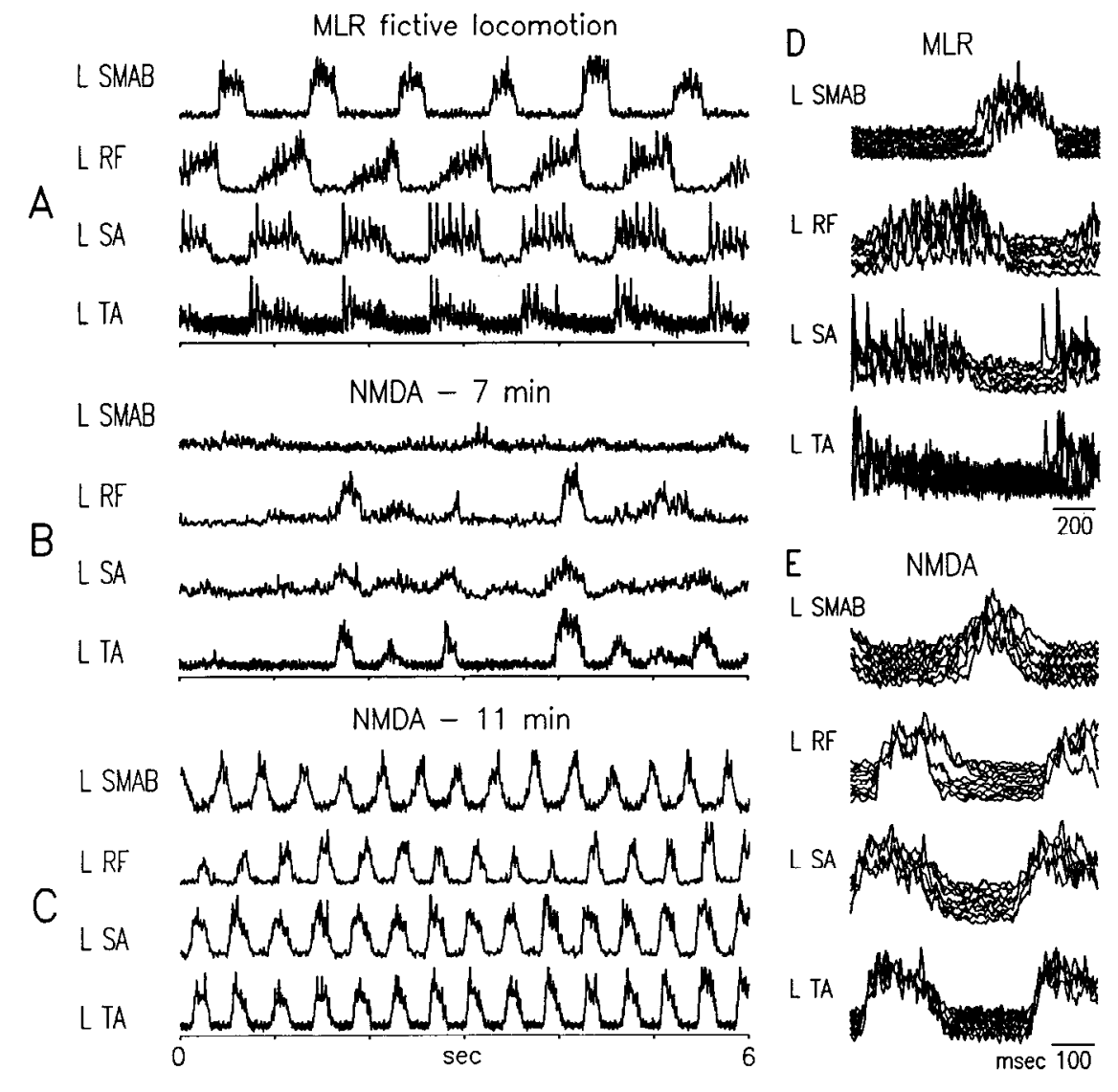

Figure 5. Comparison of NMDA- and MLR-evoked fictive locomotion. $A$, Control locomotion evoked by stimulation of the MLR $(200 \mu \mathrm{A}, 14 \mathrm{~Hz}, 1.0-$ msec-duration pulses). $B$ and $C$, The ENG bursting activity evoked by the intrathecal administration of $5 \mathrm{~mm}$ NMDA, first evident within $7 \mathrm{~min}(B)$, was well developed within $11 \mathrm{~min}(C)$. The frequency of the NMDA-evoked fictive locomotion $(2.4 \mathrm{~Hz})$ was greater than that observed with the MLRevoked locomotion in $A(1 \mathrm{~Hz}) . D$ and $E$, Rasters of 8 and 12 step cycles during fictive locomotion evoked by either MLR stimulation or NMDA, respectively. The start of activity in the L SA nerve was used to define the onset of each step cycle. Average cycle durations were $1003 \pm 62$ and $413 \pm 14 \mathrm{msec}$ for $D$ and $E$, respectively. Waveform gains in $A-C$ are different from those in $D$ and $E$.
Intrathecal administration of NMDA given together with or shortly after (20-91 min) DHK evoked locomotion in five of five experiments. This was observed in the one animal that had previously received APV (Fig. $7 D$ ) and in the one spinal animal (Fig. $8 B$ ). Effective concentrations of NMDA and DHK ranged, respectively, from 0.5 to 2.5 and from 0.5 to $5 \mathrm{~mm}$ when given together and were $5 \mathrm{~mm}$ when given separately. Locomotion commenced within $2-13 \mathrm{~min}$ and could be maintained for up to $30 \mathrm{~min}$ after a given dose of NMDA and DHK. In three animals, the locomotion progressively increased in frequency during the latter half of this period. At lower stepping frequencies (below $3.5 \mathrm{~Hz}$ ), NMDA/DHK-evoked locomotion was similar to that evoked by stimulation of the MLR with reciprocal alternation between flexors and extensors, bilaterally (compare Fig. $7, A, D$ and $E, F$ ). In this experiment, the cycle frequency increased beyond $3.5 \mathrm{~Hz}$ and eventually reached a rate of $6 \mathrm{~Hz}$, far greater than the mean cycle frequency observed for overground unrestrained locomotion (Goslow et al., 1973). Even at this rate, the pattern of alternation between flexors and extensors was for the most part maintained (Fig. 7G). Eventually the interand intralimb coordination broke down and the amplitude of the high-frequency bursts diminished. In contrast to the results obtained with NMDA/DHK, intrathecal administration of 5 $\mathrm{mm}$ GLU/DHK did not result in any locomotor activity in the one animal tested.

In two of the fictive locomotion experiments (one decerebrate and one spinalized), episodes of high-frequency rhythmic activity occasionally interrupted the locomotion evoked by intrathecal injection of NMDA/DHK. This is illustrated in Figure 8 for the spinal cat. The frequency $(7.5 \mathrm{~Hz})$ was faster than that re- ported for fictive scratch by Deliagina et al. (1975). The pattern described for fictive scratch by these authors (very long flexor bursts alternating with short extensor bursts) was not apparent in our experiments. Although fictive paw shake has not yet been characterized, the frequency and sequence of nerve activation (particularly the coactivation of QUAD and TA) in our experiments are similar to the pattern seen in the paw-shake responses of nonparalyzed spinal cats (Smith et al., 1985; Koshland and Smith, 1989).

\section{Effects of intrathecal QUIS/KAIN}

In two fictive locomotion experiments, intrathecal administration of $5 \mathrm{~mm}$ QUIS/KAIN increased the tonic discharge of all recorded hindlimb nerves within 5-6 min. This increased discharge lasted up to $27 \mathrm{~min}$. Rhythmic discharges occasionally interrupted this increased tonic activity (Fig. 6C) but locomotion was never observed.

\section{Discussion}

From the experiments performed in this study, we conclude that the locomotor rhythm/pattern generator in the adult mammal has at least two EAA receptor components (NMDA and nonNMDA) and that the activation of thesc receptors is necessary for the production of hindlimb locomotion in the adult cat. We base this conclusion upon results obtained following intrathecal administration of EAA agonists and antagonists. (1) Intrathecal injection of NMDA or NMDA and DHK together produced locomotor activity similar to that obtained with electrical stimulation of the MLR. (2) Intrathecal infusion of either the NMDA 


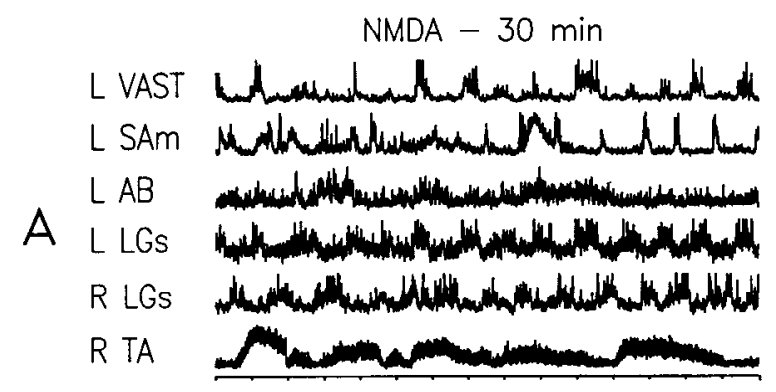

DHK - 15 min
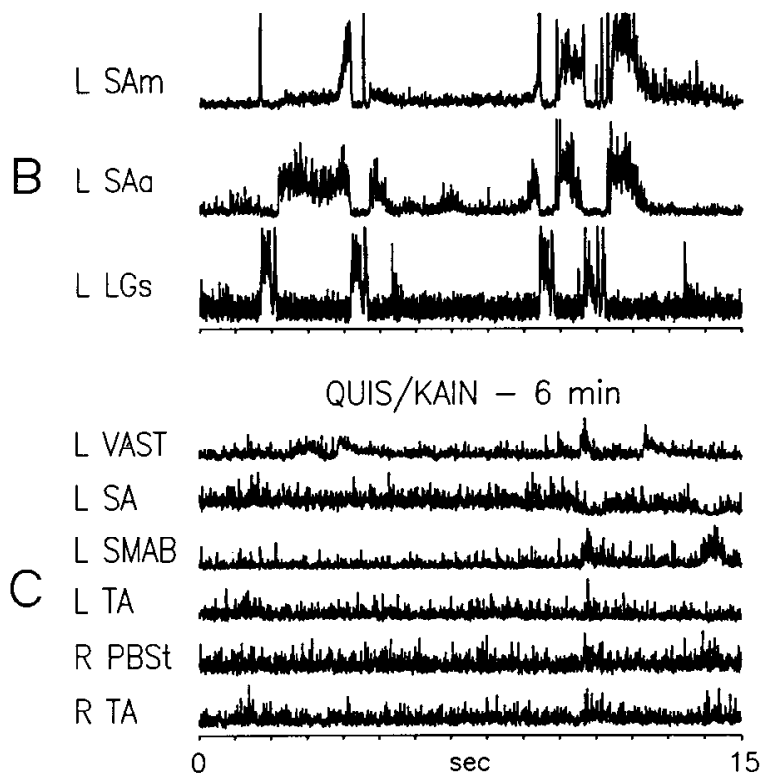

Figure 6. Effects of intrathecal administration of either NMDA $(A)$, DHK $(B)$, or QUIS/KAIN $(C)$ in nonspinalized, decerebrate cats. Low concentrations of NMDA (1 mM) evoked "locomotor-like" activity without fully developed reciprocity between antagonists $(A)$. Intrathecal injection of $5 \mathrm{~mm}$ DHK produced erratic bursting activity with welldeveloped reciprocity between antagonists $(B)$. In contrast, intrathecal injection of $5 \mathrm{mM}$ QUIS/KAIN resulted in increased tonic activity and the occasional burst of activity from all ENGs $(C)$.

receptor antagonist APV or the non-NMDA receptor antagonist CNQX reversibly blocked MLR-evoked locomotion.

The conclusion that spinal EAA receptors are involved in the generation of mammalian locomotion is supported by data obtained from other species. For example, NMDA evokes locomotion and NMDA receptor antagonists block the locomotion evoked by a variety of methods in the lamprey (Grillner et al., 1981, 1987; Brodin and Grillner, 1985a; Brodin et al., 1985), amphibian (Roberts et al., 1983, 1986; Dale and Roberts, 1984; McClellan and Farel, 1985), chick (Barry and O'Donovan, 1987), neonatal rat (Kudo and Yamada, 1987; Smith et al., 1988; Schmidt et al., 1989; Atsuta et al., 1991), and rabbit (Fenaux et al., 1991). KAIN also evokes swimming in the lamprey (Grillner et al., 1981; Brodin ct al., 1985) and spinal amphibian (Dale and Roberts, 1984; Roberts et al., 1986) and KAIN antagonists block sensory-, propriospinal neuron-, and brainstem-evoked swimming in the lamprey (Brodin and Grillner, 1985a; Dale, 1986; Grillner et al., 1987) and amphibian (Dale and Roberts, 1984; Roberts et al., 1986). Using the QUIS receptor agonist AMPA, Alford and Grillner (1990) have provided evidence for the involvement of QUIS in the generation of swimming in the lamprey.

In contrast to the results obtained with non-NMDA antagonists, intrathecal administration of the non-NMDA agonists QUIS/KAIN did not result in locomotor activity. Kudo and Yamada (1987) and Smith et al. (1988) have also reported some difficulties in evoking locomotion using these drugs that may be related to their rapid uptake (see Alford and Grillner, 1990) or to the possibility that the drugs are only effective in evoking locomotion over a limited concentration range (Kudo and Yamada, 1987).

In the present study, administration of DHK, while never resulting in fictive locomotion, evoked rhythmic bursts of activity characterized by a high degree of reciprocity between flexors and extensors. DHK blocks the uptake of GLU and aspartate (Johnston et al., 1974, 1979; Lodge et al., 1979, 1980) and results in elevated levels of these substances in the extracellular space (Brodin et al., 1988). Since DHK is a poor excitant of cat spinal neurons (Johnston et al., 1974), the action of DHK observed in the present study is most likely via increased levels of endogenously released GLU and aspartate that may then activate both NMDA and non-NMDA receptors (Mayer and Westbrook, 1987). Likewise, since NMDA is not actively transported by the EAA uptake system (Balcar and Johnston, 1972; Cox et al., 1977), and since DHK does not potentiate the action of NMDA on spinal neurons (Lodge et al., 1979) and has no or only a small potentiating effect on NMDA-evoked locomotion in the lamprey (Brodin and Grillner, 1985b), the locomotion evoked by DHK and low concentrations of NMDA appears to be the result of the additive effect of both drugs.

The fact that DHK could not evoke consistent periods of locomotion is in contrast with the results obtained by Smith et al. (1988) for the neonatal rat. However, several explanations may account for this difference. For example, a greater diffusional distance and the presence of a functional vasculature capable of clearance would decrease the ease of penetration of the drug into the adult spinal cord in vivo. Uptake processes and kinetics of uptake of the EAAs also may differ in the in vitro preparation where the spinal cord is typically maintained at low temperatures to decrease metabolic ratc. In addition, the neonatal rat does not have fully developed descending pathways (Prendergast and Shusterman, 1982), the terminals of which may significantly contribute to the uptake of EAAs (see Potashner and Tran, 1985). Thus, the failure to evoke locomotion with DHK or GLU/DHK in the present experiments is likely related to an insufficient block of the uptake of endogenously released or exogenously applied EAAs and thus a failure to maintain an adequate concentration of the agonist in the interstitial space.

The role played by different spinal cord regions in the generation and coordination of locomotor activity is not well understood. Deliagina et al. (1983) have provided evidence for a differential distribution in the capacity of the L3-S1 segments to generate fictive scratching. However, it would appear that the results of the present study are due to actions of the drugs in the mid/caudal lumbar segments since intravenous L-dopa can elicit locomotor activity in spinal cats providing that the spinal cord is not transected caudal to the L5 segment (Grillner and Zangger, 1979).

Although the sites of action of the drugs in the different segments are not known, several possibilities exist.

(1) Motoneurons have NMDA and non-NMDA receptors (for 
MLR fictive locomotion

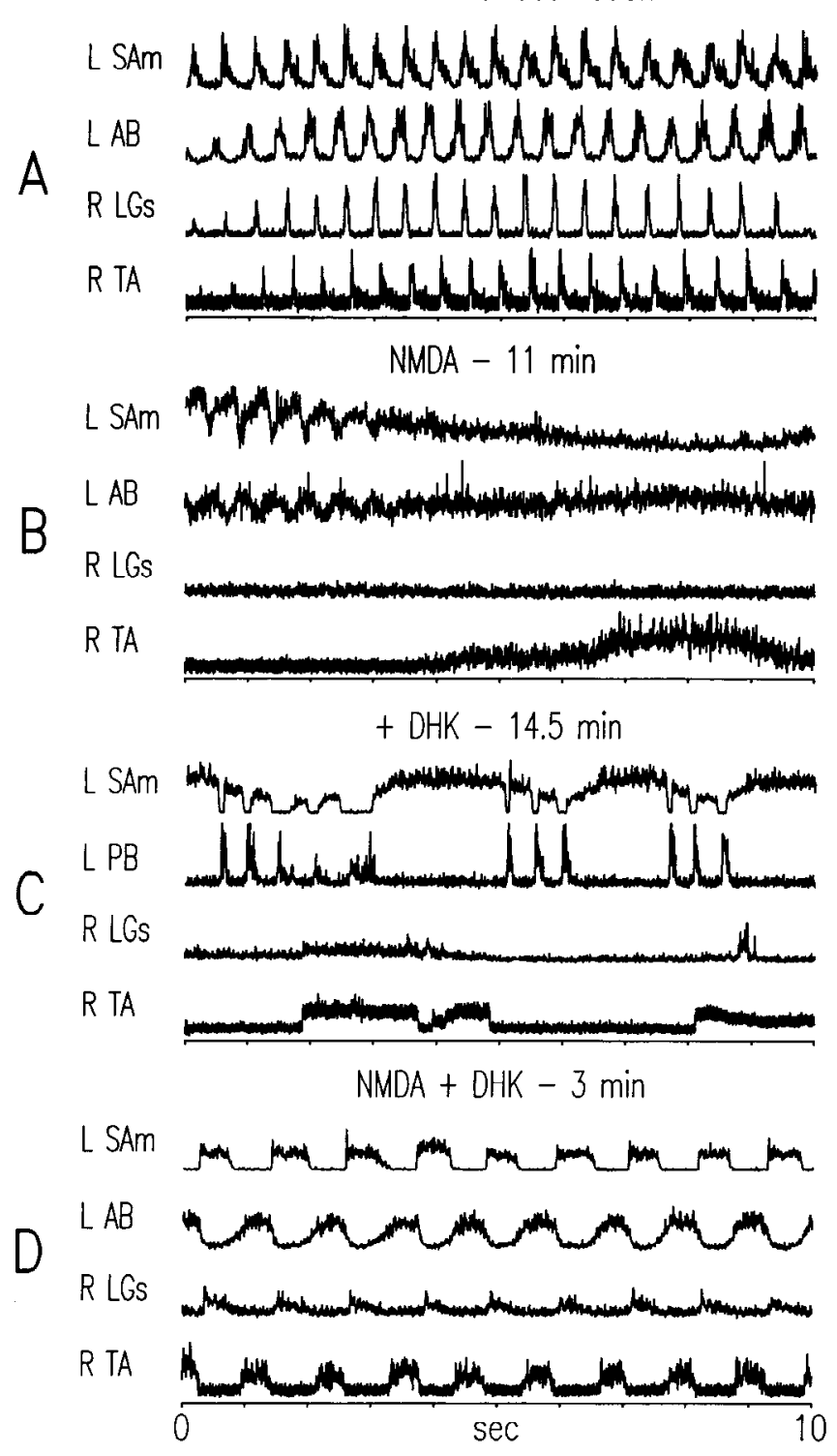

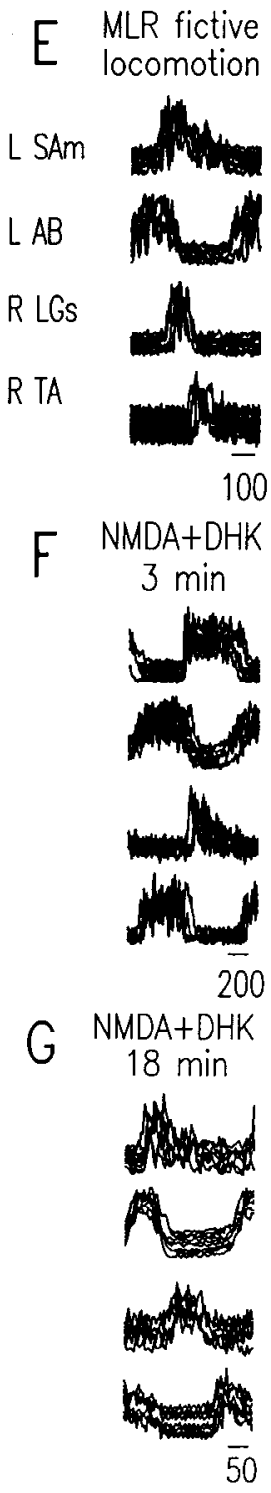

Figure 7. Intrathecal administration of NMDA and DHK together produces fictive locomotion most resembling MLR-evoked locomotion (150 $\mu \mathrm{A}, 15$ $\mathrm{Hz}, 1.0$-msec-duration pulses) $(A)$. Administration of $5 \mathrm{~mm}$ NMDA, while evoking bursting activity in most nerves $(B)$, did not produce the reciprocal activity observed following the addition of $5 \mathrm{~mm}$ DHK, 32 min later $(C)$. Intrathecal administration of NMDA/ DHK (2.5 mM), given $60 \mathrm{~min}$ later, evoked fictive locomotion showing both components of rhythmicity and reciprocity $(D)$ within 3 min. $E-G$, Rasters of 16 sequential steps during fictive locomotion evoked by either MLR stimulation $(A)$ or combined intrathecal administration of NMDA and DHK $(D)$. The onset of each step cycle was defined by the start of activity in the $\mathrm{LAB}$ nerve. Average cycle durations were $480 \pm 23$, $1125 \pm 55$, and $291 \pm 8 \mathrm{msec}$ for $E$, $F$, and $G$, respectively. Waveform gains in $E-G$ are different from those in $A-$ D. review, see Mayer and Westbrook, 1987; Collingridge and Lester, 1989) that may be important in the generation of motoneuron excitation during locomotion (Roberts et al., 1983, 1986; Dale and Roberts, 1984; Dale and Grillner, 1986). It is possible that selective blockade of these NMDA and non-NMDA receptors with APV and CNQX may have contributed to a decrease in the amplitude of the ENG/EMG bursts. However, this would not explain the disruption of the rhythm of locomotion observed following both antagonists. In addition, it is highly unlikely that NMDA and NMDA/DHK could produce coordinated activation of different nerves if their action was confined to the motoneuron EAA receptors.

(2) Another possible site of action of the drugs used in this study is the synapse made by the descending terminals of the brainstem locomotor pathway onto spinal neurons responsible for the generation of the locomotor cycle. The descending command pathway originates from reticulospinal neurons (see Jordan, 1986, 1991, for review). To date, the transmitter(s) used at the spinal cord level by the descending locomotor pathway has not been identified. Grillner et al. (1987) have reported that brainstem-evoked locomotion in the lamprey may be blocked by the EAA antagonist cis-2,3-piperidine dicarboxylate. Smith et al. (1988) have reported that bath application of APV to the spinal cord suppresses the rhythmic locomotor activity generated by chemical activation of the brainstem circuitry in the neonatal rat, thus implicating spinal NMDA receptors. However, it is not clear whether the locomotion evoked in the latter study was due to activation of pathways originating from the medial or the lateral reticular formation (cf. Noga et al., 1991). This consideration is important since the medial reticular formation mediates MLR-evoked locomotion (Noga et al., 1991), whereas the locomotor areas of the lateral reticular formation mediate sensory-evoked locomotion either with or without the participation of the medial reticular formation (Noga et al., 1988, 1991). More recently, Fenaux et al. (1991) have shown that systemic administration of the NMDA receptor antagonist MK-801 blocks the locomotion evoked by stimulation of the MLR in the decerebrate rabbit. However, it is unclear whether or not MK-801 acted at the brainstem or spinal level in this study. 
A

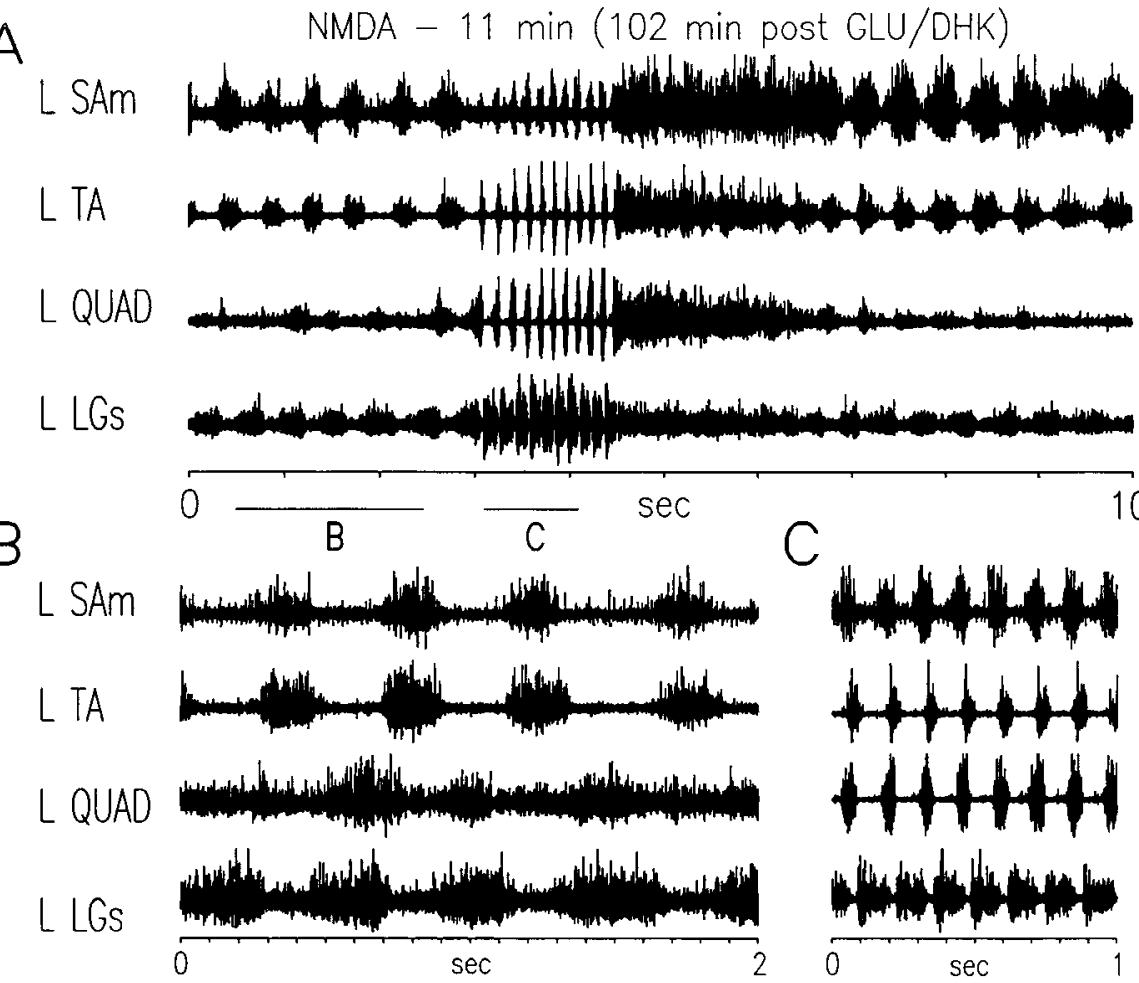

Figure 8. Occurrence of a spontaneous fictive "paw-shake" episode during drug-evoked fictive locomotion $(A) 11$ min after intrathecal administration of 5 mM NMDA. The animal had previously received $5 \mathrm{~mm}$ GLU/DHK and was spinalized at the T13 level. $B$ and $C$, Expanded portions of the locomotor and paw-shake episodes indicated by lines in $A$. Note that the expanded portions in $B$ and $C$ are at the same time scale but are at different gains. Note change in timing in the QUAD nerve response relative to the flexor and extensor bursts during the paw-shake episode.
Buchanan et al. (1987) and Ohta and Grillner (1989) have shown that reticulospinal neurons release a transmitter that acts on NMDA and non-NMDA receptors in the lamprey spinal cord. If a similar situation exists in mammals and if APV and CNQX act at this synaptic site in our experiments, one might expect a decline in the frequency of locomotion with the interruption of the descending drive to the spinal circuitry for locomotor rhythm generation (see Legendre et al., 1985). Such an effect was observed following the intrathecal injection of CNQX and APV. However, if such an antagonism occurred at the synapse between the descending pathway and the spinal neurons responsible for the generation of the locomotor cycle, it was clearly not the only site of action of APV because the step cycle frequency initially remained unaltered as the amplitude of the steps decreased (Fig. 2). The fact that NMDA and NMDA/DHK evokes locomotion demonstrates that the drugs activate the neurons responsible for generation of the locomotor rhythm. Although the synaptic site at which the EAA receptors are located remains unknown, in all likelihood these cells are also excited directly by descending reticulospinal terminals (Jordan, 1986, 1991; Noga, 1988; Jordan and Noga, 1991).

(3) Finally, the drugs used in this study could have acted at the synaptic contacts made between spinal interneurons. The fact that EAAs are powerful excitants on spinal neurons and may play an important role in synaptic transmission in the spinal cord (Johnston et al., 1974; Davies and Watkins, 1983; for review, see Mayer and Westbrook, 1987; Collingridge and Lester, 1989) supports this possibility. Rhythmically active spinal interneurons, which are activated by stimuli applied to the MLR (Noga, 1988; Shefchyk et al., 1990; Jordan and Noga, 1991), are distributed over wide areas of the spinal cord, in laminae V-VIII of the L4-L7 segments of the spinal cord (Noga et al., 1987; Fortier et al., 1988; Noga, 1988; Dai et al., 1990; cf. Jankowska and Noga, 1990). A more detailed analysis is clearly required to assess the effects of various EAA agonists on identified spinal neurons and the effects of EAA antagonists on the activity of these cells during MLR-evoked locomotion.

The high concentration of NMDA receptors in the superficial dorsal horn of the adult mouse (Gonzalez et al., 1990) and human (Jansen et al., 1990) indicates that dorsal horn neurons would most likely be affected by intrathecal infusion of NMDA agonists and antagonists. In the APV experiments, a general decrease in spinal cord excitability might have contributed to the loss of locomotion through sensory depression due to blockade of dorsal horn NMDA receptors. It might then be expected that administration of APV would have a greater effect on treadmill locomotion than on fictive locomotion. This was not seen in the present experiments. In fact, administration of $10 \mathrm{~mm}$ APV to the dorsal spinal cord area in one experiment failed to block MLR-evoked locomotion. While our results indicate that activation of dorsal horn neurons is not central to the generation of locomotion, the vigorous hindlimb flexion elicited by administration of NMDA alone in our experiments could be a response to the activation of neurons involved in nociceptive reflex pathways (Raigorodsky and Urca, 1987).

Considering the wide distribution of EAA receptors in the spinal cord and the widespread effect of EAAs on spinal neurons (for review, see Mayer and Westbrook, 1987; Collingridge and Lester, 1989), one would expect that the effects of intrathecal drug injection would not be restricted to the activation of cells confined to the production of locomotion. Regardless of whether spinal neurons are shared for different motor behaviors, the appearance of motor tasks other than locomotion would imply that a different rhythm/pattern generator from the one evoking locomotion is active. Thus, it is possible to account for the occasional periods of paw shake seen after NMDA and DHK administration (Fig. 8). In this context, it is important to note that intrathecal injection of NMDA evoked independent burst- 
ing activity in the different flexor and extensor motor pools. This observation could be taken as evidence supporting the unit burst hypothesis for the organization of the central rhythm/ pattern generator for locomotion as proposed by Grillner (Edgerton et al., 1976; Grillner, 1981). According to this hypothesis, separate populations of interneurons control the firing of each muscle. Complete uncoupling of the unit burst generators would produce independent bursting activity from the different motor pools in the limb such as that observed after NMDA administration in these experiments. This is the first evidence that demonstrates that such independent bursting is possible. However, these results should be interpreted with caution since independent bursting activity might be produced by direct activation of NMDA receptors on the motoneurons themselves. For example, ionophorctic application of NMDA onto individual motoneurons can produce pacemaker-like membrane potential oscillations (Engberg et al., 1984). Furthermore, if spinal interneurons are involved in the generation of the bursting activity observed from ENG recordings, they may not necessarily be the same spinal neurons involved in producing locomotion.

In conclusion, the experiments described in this study demonstrate that antagonism of spinal NMDA and non-NMDA receptors is sufficient to block MLR-induced stepping in adult decerebrate cats. Intrathecal administration of low concentrations of NMDA evoked "locomotor-like" bursting activity, lacking only in the reciprocal inhibition between antagonists typically observed with MLR stimulation. In contrast, intrathecal administration of DHK evoked short periods of rhythmic activity characterized by a high degree of reciprocity between antagonists but failed to evoke sustained locomotor activity. The combination of NMDA with DHK consistently elicited locomotion similar to that seen following MLR stimulation or following higher concentrations of NMDA. Taken together, the data provide evidence for the suggestion that spinal NMDA and non-NMDA receptors play a role in the initiation of locomotion in the adult mammal.

\section{References}

Alford S, Grillner S (1990) CNQX and DNQX block non-NMDA synaptic transmission but not NMDA-cvoked locomotion in lamprey spinal cord. Brain Res 506:297-302.

Atsuta Y, Abraham P, Iwahara T, Garcia-Rill E, Skinner RD (1991) Control of locomotion in vitro: II. Chemical stimulation. Somatosens Mot Res 8:55-63.

Balcar VJ, Johnston GAR (1972) The structural specificity of the high affinity uptake of L-glutamate and L-aspartate by rat brain slices. J Neurochem 19:2657-2666.

Barry MJ, O'Donovan MJ (1987) The effects of excitatory amino acids and their antagonists on the generation of motor activity in the isolated chick spinal cord. Dev Brain Res 36:271-276.

Brodin L, Grillner S (1985a) The role of putative excitatory amino acid neurotransmitters in the initiation of locomotion in the lamprey spinal cord. I. The effects of excitatory amino acid antagonists. Brain Res 360:139-148.

Brodin L, Grillner S (1985b) The role of putative excitatory amino acid neurotransmitters in the initiation of locomotion in the lamprey spinal cord. II. The effects of amino acid uptake inhibitors. Brain Res 360:149-158.

Brodin L, Grillner S, Rovainen CM (1985) N-methyl-D-aspartate (NMDA), kainate and quisqualate receptors and the generation of fictive locomotion in the lamprey spinal cord. Brain Res 325:302306.

Brodin L, Tossman U, Ohta Y, Ungerstedt U, Grillner S (1988) The effect of an uptake inhibitor (dihydrokainate) on endogenous excitatory amino acids in the lamprey spinal cord as revealed by microdialysis. Brain Res 458:166-169.
Buchanan JT, Brodin L, Dale N, Grillner S (1987) Reticulospinal neurones activate excitatory amino acid receptors. Brain Res 408 321-325.

Cazalets JR, Grillner P, Menard I, Cremieux J, Clarac F (1990) Two types of motor rhythm induced by NMDA and amines in an in vitro spinal cord preparation of neonatal rat. Neurosci Lett 111:116-121.

Cohen AH, Wallén P (1980) The neuronal correlate of locomotion in fish: "fictive swimming" in an in vitro preparation of the lamprey spinal cord. Exp Brain Res 41:11-18.

Collingridge GL, Lester RAJ (1989) Excitatory amino acid receptors in the vertebrate central nervous system. Pharmacol Rev 40:143-210.

Cox DWG, Headley PM, Watkins JC (1977) Actions of L- and Dhomocysteate in rat CNS: a correlation between low-affinity uptake and the time courses of excitation by microelectrophoretically applied L-glutamate analogues. J Neurochem 29:579-588.

Dai X, Douglas JR, Nagy JI, Noga BR, Jordan LM (1990) Localization of spinal neurons activated during treadmill locomotion using the c-fos immunohistochemical method. Soc Neurosci Abstr 16:889.

Dale N (1986) Excitatory synaptic drive for swimming mediated by amino acid receptors in the lamprey. J Neurosci 6:2662-2675.

Dale N, Grillner S (1986) Dual-component synaptic potentials in the lamprey mediated by excitatory amino acid receptors. J Neurosci 6:2653-2661.

Dale N, Roberts A (1984) Excitatory amino acid receptors in Xenopus embryo spinal cord and their role in the activation of swimming. $J$ Physiol (Lond) 348:527-543.

Davies J, Watkins JC (1983) Role of excitatory amino acid receptors in mono- and polysynaptic excitation in the cat spinal cord. Exp Brain Res 49:280-290.

Deliagina TG, Feldman AG, Gelfand IM, Orlovsky GN (1975) On the role of central program and afferent inflow in the control of scratching movements in the cat. Brain Res 100:297-313.

Deliagina TG, Orlovsky GN, Pavlova GA (1983) The capacity for generation of rhythmic oscillations is distributed in the lumbosacral spinal cord of the cat. Exp Brain Res 53:81-90.

Douglas JR, Dai X, Noga BR, Jordan LM (1990) NMDA receptor antagonists block brainstem-evoked locomotion in decerebrate cats. Soc Neurosci Abstr 16:728.

Edgerton VR, Grillner S, Sjöström A, Zangger P (1976) Central generation of locomotion in vertebrates. In: Advances in behavorial biology, Vol 18, Neural control of locomotion (Herman RM, Grillner S, Stein PSG, Stuart DG, eds), pp 439-464. New York: Plenum.

Elliott KAC, Jasper HH (1949) Physiological salt solutions for brain surgery: studies of local $\mathrm{pH}$ and pial vessel reactions to buffered and unbuffered isotonic solutions. J Neurosurg 6:140-152.

Engberg I, Flatman JA, Lambert JDC (1984) Bistable behaviour of spinal cord motoneurones during amino-acid excitation. Acta Physiol Scand 121:A6.

Fenaux F, Corio M, Palisses R, Viala D (1991) Effects of an NMDAreceptor antagonist, $\mathrm{MK}-801$, on central locomotor programming in the rabbit. Exp Brain Res 86:393-401.

Fortier P, Kriellaars D, Jordan LM (1988) Mapping of lumbar cord potentials evoked by stimulation of the mesencephalic locomotor region (MLR) in the cat. Soc Neurosci Abstr 14:264.

Garcia-Rill E (1986) The basal ganglia and the locomotor regions. Brain Res Rev 11:47-63.

Gonzalez DL, Fuchs JL, Droge MH (1990) The distribution of $N$-methyl-D-aspartic acid receptor binding in neonatal and adult mouse lumbar spinal cord. Soc Neurosci Abstr 16:90.

Goslow GE Jr, Reinking RM, Stuart DG (1973) The cat step cycle: hind limb joint angles and muscle lengths during unrestrained locomotion. J Morphol 141:1-42.

Grillner S (1981) Control of locomotion in bipeds, tetrapods, and fish. In: Handbook of physiology, Sec 1, The nervous system, Vol II, Motor control, Pt 2 (Brookhart JM, Mountcastle VB, eds), pp 1179-1236. Bethesda, MD: American Physiological Society.

Grillner S, Zangger P (1979) On the central generation of locomotion in the low spinal cat. Exp Brain Res 34:241-261.

Grillner S, McClellan A, Sigvardt K, Wallén P, Wilen M (1981) Activation of NMDA-receptors elicits "fictive locomotion" in lamprey spinal cord in vitro. Acta Physiol Scand 113:549-551.

Grillner S, Wallén P, Dale N, Brodin L, Buchanan J, Hill R (1987) Transmitters, membrane properties and network circuitry in the control of locomotion in lamprey. Trends Neurosci 10:34-41.

Honore T, Davies SN, Drejer J, Fletcher EJ, Jacobsen P, Lodge D, 
Nielsen FE (1988) Quinoxalinediones: potent competitive nonNMDA glutamate receptor antagonists. Science 241:701-703.

Jankowska E, Noga BR (1990) Contralaterally projecting lamina VIII interneurones in middle lumbar segments in the cat. Brain Res 535: 327-330.

Jansen KLR, Faull, RLM, Dragunow M, Waldvogel H (1990) Autoradiographic localisation of NMDA, quisqualate and kainic acid receptors in human spinal cord. Neurosci Lett 108:53-57.

Johnston GAR, Curtis DR, Davies J, McCulloch RM (1974) Spinal interncurones excitation by conformationally restricted analogues of L-glutamic acid. Nature 248:804-805.

Johnston GAR, Kennedy SME, Twitchin B (1979) Action of the neurotoxin kainic acid on high affinity uptake of L-glutamic acid in rat brain slices. J Neurochem 32:121-127.

Jordan LM (1986) Initiation of locomotion from the mammalian brainstem. In: Wenner-Gren Centre international symposium series, Vol 45, Neurobiology of vertebrate locomotion (Grillner S, Stein PSG, Stuart DG, Forssberg H, Herman RM, eds), pp 21-37. London: Macmillan.

Jordan LM (1991) Brainstem and spinal cord mechanisms for the initiation of locomotion. In: Neurobiological basis of human locomotion (Shimamura S, Grillner S, Edgerton VR, eds), pp 3-30. Tokyo: Japan Scientific Societies.

Jordan LM, Noga BR (1991) Spinal interncurons synaptically activated by stimuli applied to the mesencephalic locomotor region. Soc Neurosci Abstr 17:1223.

Jordan LM, Pratt CA, Menzies JE (1979) Locomotion evoked by brain stem stimulation: occurrence without phasic segmental afferent input. Brain Res 177:204-207.

Koshland GF, Smith JL (1989) Mutable and immutable features of paw-shake responses after hindlimb deafferentation in the cat. J Neurophysiol 62:162-173.

Kudo N; Yamada T (1987) $N$-methyl-D,L-aspartate-induced locomotor activity in a spinal cord-hindlimb muscles preparation of the newborn rat studied in vitro. Neurosci Lett 75:43-48.

Legendre P, McKenzie JS, Dupouy B, Vincent JD (1985) Evidence for bursting pacemaker neurones in cultured spinal cord cells. Neuroscicncc 16:753-767.

Lodge D, Johnston GAR, Curtis DR, Bornstein JC (1979) Kainate neurotoxicity and glutamate inactivation. Neurosci Lett 14:343-348.

Lodge D, Curtis DR, Johnston GAR, Bornstein JC (1980) In vivo inactivation of quisqualate: studies in the cat spinal cord. Brain Res 182:491-495.

Mayer ML, Westbrook GL (1987) The physiology of excitatory amino acids in the vertebrate central nervous system. Prog Neurobiol 28: 197-276.

McClellan AD, Farel PB (1985) Pharmacological activation of locomotor patterns in larval and adult frog spinal cords. Brain Res 332: $119-130$.

Noga BR (1988) An investigation of descending brainstem pathways involved in the production of locomotion. $\mathrm{PhD}$ thesis, University of Manitoba.

Noga BR, Shefchyk SJ, Jordan LM (1987) Localization of last-order spinal interneurons participating in the production of locomotion in the cat. Soc Neurosci Abstr 13:826.
Noga BR, Kettler J, Jordan LM (1988) Locomotion produced in mesencephalic cats by injections of putative transmitter substances and antagonists into the medial reticular formation and the pontomedullary locomotor strip. J Neurosci 8:2074-2086.

Noga BR, Kriellaars DJ, Jordan LM (1991) The effect of selective brainstem or spinal cord lesions on treadmill locomotion evoked by stimulation of the mesencephalic or pontomedullary locomotor regions. J Neurosci 11:1691-1700.

Ohta Y, Grillner S (1989) Monosynaptic excitatory amino acid transmission from the posterior rhombencephalic reticular nucleus to spinal neurons involved in the control of locomotion in lamprey. $J$ Neurophysiol 62:1079-1089.

Poon MLT (1980) Induction of swimming in lamprey by L-dopa and amino acids. J Comp Physiol 136:337-344.

Potashner SJ, Tran PL (1985) Decreased uptake and release of Daspartate in the guinea pig spinal cord after partial cordotomy. $J$ Neurochem 44:1511-1519.

Prendergast J, Shusterman R (1982) Normal development of motor behaviour in the rat and effect of midthoracic spinal hemisection at birth on that development. Exp Neurol 78:176-189.

Raigorodsky G, Urca G (1987) Intrathecal $N$-methyl-D-aspartate (NMDA) activates both nociceptive and antinociceptive systems. Brain Res 422:158-162.

Robcrts A, Soffc SR, Clarke JDW, Dale N (1983) Initiation and control of swimming in amphibian embryos. In: Symposia of the society for experimental biology, No 37, Neural origin of rhythmic movements (Roberts A, Roberts BL, eds), pp 261-284. New York: Cambridge UP.

Roberts A, Soffe SR, Dale N (1986) Spinal interneurones and swimming in frog embryos. In: Wenner-Gren Centre international symposium series, Vol 45, Neurobiology of vertebrate locomotion (Grillner S, Stein PSG, Stuart DG, Forssberg H, Herman RM, eds), pp 279-306. London: Macmillan.

Schmidt BJ, Smith JC, Feldman JL (1989) Involvement of excitatory amino acids in neurotransmission of rhythmic excitatory drive to motoneurons during locomotion in the rat spinal cord in vitro. Soc Neurosci Abstr 15:505.

Shefchyk SJ, McCrea D, Kriellaars D, Fortier P, Jordan L (1990) Activity of interneurons within the L4 spinal segment of the cat during brainstem-evoked fictive locomotion. Exp Brain Res 80:290-295.

Shik ML, Orlovsky GN, Severin FV (1968) Locomotion of the mesencephalic cat elicited by stimulation of the pyramids. Biophysics 13: 143-152.

Smith JC, Feldman JL (1987) In vitro brainstem-spinal cord preparations for study of motor systems for mammalian respiration and locomotion. J Neurosci Methods 21:321-333.

Smith JC, Feldman JL, Schmidt BJ (1988) Neural mechanisms generating locomotion studied in mammalian brain stem-spinal cord in vitro. FASEB J 2:2283-2288.

Smith JL, Hoy MG, Koshland GF, Phillips DM, Zernicke RF (1985) Intralimb coordination of the paw-shake response: a novel mixed synergy. J Neurophysiol 54:1271-1281. 